\title{
How different domains of quality of life are associated with latent dimensions of mental health measured by GHQ-12
}

Fatemeh Nouri ${ }^{1,2,3}$, Awat Feizi ${ }^{2,4^{*}} \mathbb{0}$, Hamidreza Roohafza ${ }^{5}$, Masoumeh Sadeghi and Nizal Sarrafzadegan ${ }^{3}$

\begin{abstract}
Background and objectives: A short form of the General Health Questionnaire (GHQ-12) is a useful screening instrument for assessing mental health. Furthermore, Quality of life (QoL) is a critical treatment outcome in many clinical and health care research settings. This study aimed to reassess the dimensionality of GHQ-12 using Multidimensional Graded Response Model (MGRM) and evaluate how its extracted dimensions are associated with the QoL's domains.

Methods: Isfahan Cohort Study 2 (ICS2) is a population-based, ongoing prospective cohort study among adults aged 35 years and older who were free of cardiovascular diseases (CVDs) at the beginning of the study in 2013. A total of 1316 participants, all living in urban and rural areas of Isfahan and Najafabad, Iran was completed the GHQ-12 and WHO QoL-brief version at baseline. Five competing MGRMs with different latent structures were specified for GHQ12. Factor scores derived from the best fitted model were used to associate with various domains of QoL. Results: The Three-Dimensional model for GHQ-12 was the best-fitted model explaining the Social Function (SF), Self Confidence (SC), and Anxiety/Depression (A/D) as three correlated yet different latent dimensions of mental health. Our findings in full adjusted multivariate regression models showed that a one-SD increase in dimensions of SC and SF was associated with a 38- to 48\%-SD and 27- to 38\%-SD increase in the domains scores of QoL, respectively. Moreover, for each one-SD increase in score of A/D dimension, the domains scores of QoL decreased by 29- to 40\%-SD. The highest to the lowest standardized coefficients for all latent dimensions of mental health were respectively related to the psychological, physical health, social relationships, and environmental condition domains of QoL. Furthermore, SC, A/D, and SF dimensions of GHQ-12 showed the highest to the lowest degree of association with all domains of QoL.
\end{abstract}

Conclusions: Our findings confirm that the GHQ-12 as a multidimensional rather than unitary instrument measures distinct dimensions of mental health. Furthermore, all aspects of QoL changed when the intensity of latent dimensions of mental health increased. Moreover, the psychological domain of QoL is the most affected by all latent dimensions of mental health, followed by physical health, social relationships, and environmental condition domains. It seems that in an attempt to full recovery as assessed by improved QoL outcomes, treatment of clinical symptoms may not be sufficient. Identifying and differentiating the structures of mental health in each community as well as implementing intervention programs aimed at focusing on specific dimensions may help in the prevention of further deterioration of mental health and improved QoL in the community.

\footnotetext{
*Correspondence: awat_feiz@hlth.mui.ac.ir

${ }^{2}$ Department of Biostatistics and Epidemiology, School of Health, Isfahan

University of Medical Sciences, Hezar Jerib Street, 8174673461 Isfahan,

Iran

Full list of author information is available at the end of the article
} permits use, sharing, adaptation, distribution and reproduction in any medium or format, as long as you give appropriate credit to the original author(s) and the source, provide a link to the Creative Commons licence, and indicate if changes were made. The images or other third party material in this article are included in the article's Creative Commons licence, unless indicated otherwise in a credit line to the material. If material is not included in the article's Creative Commons licence and your intended use is not permitted by statutory regulation or exceeds the permitted use, you will need to obtain permission directly from the copyright holder. To view a copy of this licence, visit http://creativecommons.org/licenses/by/4.0/. The Creative Commons Public Domain Dedication waiver (http://creativeco mmons.org/publicdomain/zero/1.0/) applies to the data made available in this article, unless otherwise stated in a credit line to the data. 
Keywords: General Health Questionnaire (GHQ-12), Mental health, Item Response Theory, Quality of life (QoL)

\section{Introduction}

Quality of life (QoL) as a critical treatment outcome is an essential topic in mental health care and research [1]. According to the World Health Organization (WHO), QoL is "as an individual's perception of his/her position in life in the context of the culture and value systems in which he/she lives and in relation to his/her goals, expectations, standards and concerns" [2]. QoL as a multidimensional construct of objective and subjective factors comprises the individual's physical health, social relationships, psychological status, and environmental conditions [2]. Previous studies showed that almost all of the QoL aspects are vulnerable to mental health status. Patients with mental disorders such as depression, anxiety, and distress have weak QoL [3-11].

According to the WHO, mental health as a critical component of general health is "a state of well-being in which the individual realizes his or her abilities, can cope with the normal stress of life, can work productively and fruitfully, and is able to make a contribution to his or her community" [12]. The General Health Questionnaire (GHQ) is a member of the family of instruments for assessing the mental aspect of general health. It evaluates symptoms of anxiety, social dysfunction, loss of confidence, and depression [13]. Of the various versions of GHQ, e.g., the GHQ-60, GHQ-30, GHQ-28, and GHQ12 , the twelve-item questionnaire with six negative and six positive statement four-point Likert items is one of the most long-standing and extensively used measures of minor psychiatric disorders in community and primary care settings around the world [13]. Despite its widely used, the factor structure of GHQ-12 remains a controversial issue. A simple summed score of GHQ-12 is used initially as a single observed construct of the mental health severity $[4,11]$. Table 1 presents the identified GHQ-12's factor structures by the previous studies, along with the study population, applied model, and estimation methods. Some studies suggested unidimensional latent construct with or without adjusting the effects of negative/positive phrased items [14-18]. Some other studies have shown evidence of the scale containing two, three, or four latent factors as multidimensional mental health constructs [19-26]. However, some studies assessing factor structure of GHQ-12 using Exploratory and Confirmatory Factor Analysis (EFA, CFA) and Structural Equation Model (SEM) have ignored Likert-type response data in their parameter estimation methods (assuming the GHQ-12s items as continuous variables follow a normal distribution) $[15,18-20,23,27,28]$. A study aimed to compare several coding methods such as original (i.e., 1-2-3-4 scheme for four-response categories), bi-modal (i.e., 0-0-1-1 scheme), and chronic (mixed binary scheme for positively (0-0-1-1) and negatively (0-1-1-1) phrased questions) argued in favor of using original Likert format of GHQs items based on theoretical and empirical reasons [29]. Besides, according to a statistical point of view, a comparative study of multiple parameter estimation approaches concluded that the best one was the ordinal format of items for GHQ-12 factor structure [30]. A recent review article aimed to improve the assessment of health surveys demonstrated useful characteristics of a valuable and flexible model named Multidimensional Graded Response (MGR) model compared to EFA and CFA [31]. The MGR model, as a particular case of Multidimensional Item Response Theory (MIRT), can be used to define multi-component constructs as dimensions of mental health with considering the nature of ordinal responses of GHQ-12s items [31, 32].

The aims of the present study were: (1) to evaluate the latent structure of GHQ-12 within an MGR model framework in a large population-based study; (2) to examine how different aspects of QoL are associated with latent dimensions of mental health in the general population. Moreover, these associations were adjusted for a wide range of potential confounding variables such as demographic, lifestyle-related variables, and BMI $[3,6,7$, 33-35].

\section{Materials and methods}

\section{Study design and participants}

Isfahan Cohort Study (ICS) was a longitudinal population-based cohort study including a representative sample of adults aged 35 years old or over in 2001-2011 [36]. Participants were selected using a multi-stage sampling method. Details about the multistage random sampling procedure (based on urban/rural, sex, and age distribution of the community), along with data collection and study design were published previously [37, 38]. This study included Iranian adults 35 years of age or older, mentally competent and not pregnant. After obtaining informed written consent, different questionnaires, including food frequency questionnaire (FFQ), physical activity, demographic status, smoking and medical history, were completed by participants in a face-to-face interview at baseline. Also, participants underwent clinical examination, electrocardiography and laboratory evaluation. Cardiovascular diseases (CVDs) were the primary outcome events considered in the ICS. The subjects 
Table 1 The suggested GHQ-12's factor structures by the previous studies

\begin{tabular}{|c|c|c|c|c|c|}
\hline Studies & Study population & Age range & Applied model & Estimation methods & The best identified model \\
\hline Gnambs [14] & $\begin{array}{l}\text { A representative sample } \\
\text { from the population of } \\
\text { the United Kingdom or } \\
\text { one of its countries }\end{array}$ & $13-100$ years & SEM & ML, WLS & $\begin{array}{l}\text { Unidimensional factor with } \\
\text { adjusting wording effects }\end{array}$ \\
\hline Hankins [15] & $\begin{array}{l}\text { General population of } \\
\text { the UK }\end{array}$ & Not reported & SEM & $M L$ & $\begin{array}{l}\text { Unidimensional factor with } \\
\text { adjusting wording effects }\end{array}$ \\
\hline Motamed [16] & $\begin{array}{l}\text { Adult population of } \\
\text { Northern Iran }\end{array}$ & $>=18$ years & CFA & Not reported & $\begin{array}{l}\text { Unidimensional factor with } \\
\text { correlated errors on nega- } \\
\text { tive items }\end{array}$ \\
\hline Rodrigo [17] & $\begin{array}{l}\text { A representative sample } \\
\text { of all employees living in } \\
\text { Catalonia (Spain) }\end{array}$ & $17-82$ years & CFA & WLS & $\begin{array}{l}\text { Unidimensional factor with } \\
\text { adjusting wording effects }\end{array}$ \\
\hline Smith [18] & $\begin{array}{l}\text { A representative sample } \\
\text { of the ageing population } \\
\text { of the UK }\end{array}$ & $>50$ years & CFA & $\mathrm{ML}$ & $\begin{array}{l}\text { Unidimensional factor with } \\
\text { adjusting negative wording } \\
\text { effect }\end{array}$ \\
\hline $\begin{array}{l}\text { del Pilar Sánchez-López } \\
\text { [19] }\end{array}$ & $\begin{array}{l}\text { General Spanish popula- } \\
\text { tion }\end{array}$ & $25-65$ years & EFA & $\mathrm{ML}$ & $\begin{array}{l}\text { Three-factor structure, } \\
\text { including successful coping, } \\
\text { self-esteem, and stress }\end{array}$ \\
\hline El-Metwally [20] & $\begin{array}{l}\text { Al Kharj adult population } \\
\text { of Saudi Arabia }\end{array}$ & $>=18$ years & EFA & $\mathrm{ML}$ & $\begin{array}{l}\text { Three-factor structure, } \\
\text { including social dysfunc- } \\
\text { tion, anxiety, and loss of } \\
\text { confidence }\end{array}$ \\
\hline Griffith [21] & $\begin{array}{l}\text { A representative UK } \\
\text { sample }\end{array}$ & Mean $=45.8, S D=18.0$ & Exploratory SEM & $\begin{array}{l}\text { Bayesian estimation } \\
\text { and } \mathrm{ML}\end{array}$ & $\begin{array}{l}\text { Four-factor structure, } \\
\text { including lowered self- } \\
\text { worth, social dysfunction, } \\
\text { stress, and emotional } \\
\text { coping }\end{array}$ \\
\hline Mäkikangas [22] & $\begin{array}{l}\text { Finnish working-age } \\
\text { subjects }\end{array}$ & $25-59$ years & CFA & WLS & $\begin{array}{l}\text { Three-factor structure, } \\
\text { including anxiety/depres- } \\
\text { sion, social dysfunction, and } \\
\text { loss of confidence }\end{array}$ \\
\hline Montazeri [23] & $\begin{array}{l}\text { A sample of young Iranian } \\
\text { adolescents }\end{array}$ & $18-25$ years & EFA & $\mathrm{ML}$ & $\begin{array}{l}\text { Two-factor structure, includ- } \\
\text { ing psychological distress } \\
\text { and social dysfunction }\end{array}$ \\
\hline Najarkolaei [24] & $\begin{array}{l}\text { Students of University of } \\
\text { Tehran, Iran }\end{array}$ & $18-39$ years & EFA and CFA & ML and WLS & $\begin{array}{l}\text { Two-factor structure, includ- } \\
\text { ing social dysfunction and } \\
\text { psychological distress }\end{array}$ \\
\hline Namjoo [25] & Iranian elder people & $>=60$ years & CFA & WLS & $\begin{array}{l}\text { Two-factor structure, includ- } \\
\text { ing social dysfunction and } \\
\text { psychological distress }\end{array}$ \\
\hline Salama-Younes [26] & Elderly French people & $58-72$ years & CFA & Not reported & $\begin{array}{l}\text { Three-factor structure, } \\
\text { including anxiety and } \\
\text { depression, social dysfunc- } \\
\text { tion and loss of confidence }\end{array}$ \\
\hline Gao [27] & $\begin{array}{l}\text { A consecutive sample } \\
\text { of outpatients with } \\
\text { anxiety disorders and/or } \\
\text { depressive disorders in } \\
\text { Singapore }\end{array}$ & Not reported & CFA & $M L$ & $\begin{array}{l}\text { Three-factor structure, } \\
\text { including anxiety and } \\
\text { depression, social dysfunc- } \\
\text { tion and loss of confidence }\end{array}$ \\
\hline Liang [28] & $\begin{array}{l}\text { Young Chinese civil } \\
\text { servants }\end{array}$ & $20-45$ years & EFA and CFA & $M L$ & $\begin{array}{l}\text { All one-, two-, and three- } \\
\text { dimensional models were } \\
\text { well fitted }\end{array}$ \\
\hline Smith [49] & $\begin{array}{l}\text { Cancer patients with } \\
\text { heterogeneous diagnoses } \\
\text { in the UK }\end{array}$ & $\begin{array}{l}\text { Late middle age with } \\
\text { mean }=57.42\end{array}$ & IRT, CFA & $\mathrm{ML}$ & $\begin{array}{l}\text { Unidimensional factor with } \\
\text { correlated error terms }\end{array}$ \\
\hline Abubakar [50] & $\begin{array}{l}\text { A population of Kenyan } \\
\text { adults and adolescents }\end{array}$ & $12-60$ years & CFA & Not reported & $\begin{array}{l}\text { Three-factor structure, } \\
\text { including anxiety, social } \\
\text { dysfunction and loss of } \\
\text { confidence }\end{array}$ \\
\hline
\end{tabular}


Table 1 (continued)

SEM structural equation model, $M L$ maximum likelihood, WLS weighted least square, CFA confirmatory factor analysis, EFA exploratory factor analysis, IRT item response theory

who had a previous history of CVD were excluded at the beginning of the study. Remaining participants were biannually followed-up to detect major CVD. In 2013, ICS was considered a master plan for a multi-generation 10-year cohort study named Isfahan Cohort Study 2 (ICS2) [37]. ICS2 was included a sub-sample of ICS $(\mathrm{n}=1487)$ and a new recruited sample $(\mathrm{n}=1355)$ aged 35 years and over, all living in urban and rural areas of Isfahan and Najafabad, who were initially free of CVDs [37]. The study was approved by the Ethics Committee of Isfahan Cardiovascular Research Center, a World Health Organization collaborating center. All participants provided written informed consent to participate in the study. In the current study, of 1355 newly recruited participants in ICS2 started at 2013, data of 1316 new cases, who had complete information on all variables were included for data analysis.

\section{Study instruments and data collection Assessment of sociodemographic characteristics}

Trained nurses and physicians performed an interview in 2013 to identify the participants' sociodemographic characteristics, including sex (female/male), age (years), marital status (married/single, divorced, widowed)), place of residence (rural/urban), and educational attainment years $(0-5$ year/6-12 years/ > 12 years $)$.

\section{Assessment of lifestyle-related variables}

Information on lifestyle behaviors, including dietary behaviors, physical activity, coping strategies and smoking status (ever (current and past) /never) were collected through face-to-face interviews. Moreover, body mass index (BMI) was defined as weight $(\mathrm{kg}) /$ height $\left.^{2}(\mathrm{~m})\right)$. In the current study, we used the International Physical Activity Questionnaire (IPAQ), whose reliability and validity findings were previously published $[39,40]$. The total score of an individual's physical activity (expressed as metabolic equivalent task minutes per day (MET$\mathrm{m} / \mathrm{d}$ )) consisted of four fields, including homework, leisure time, worksite, and transportation. We categorized total physical activity based on its tertiles in our analysis. To assess adaptive and maladaptive coping strategies validated stress management questionnaire was used [41]. Every one of 30 items is responded to a three-point scale (never, sometimes, and often). For scoring in each individual, the number of items answered "often" is divided by the number of items answered "often" and "sometimes" and is considered the percentage of maladaptive and adaptive skills.
Dietary intake information was evaluated with a validated qualitative, 48-item food frequency questionnaire (FFQ) [42]. Participants answered the frequency of consumption of each item in FFQ in the previous year. Diet quality index (DQI) focused on seven food groups, including fish, soy protein, chicken, or legumes; animal fats, ghee, butter, or hydrogenated oil; fast food; sweets; whole dairy products, meat, or egg; fruit and vegetables; and non-hydrogenated and olive oil. Individual responses of the frequency of consumption in seven food groups were categorized as 2,1 , or 0 , in which a higher score reflected a lower nutritional value. The DQI's total score was computed by summing the responses dividing by the number of items. Higher scores of DQI (ranged from 0 to 2 ) indicate low or unhealthy diet quality. The DQI was previously described in detail [43].

\section{Assessment of mental health}

GHQ-12, as a brief and self-administered questionnaire, was used to evaluate mental health and short-term changes in mental health. Every one of its 12 items is responded to a four-point Likert scale. It consists of six negatives statement items (with response scale including not at all; no more than usual; rather more than usual and much more than usual) and six positive statement items (with a response scale including more than usual; same as usual; less than usual and much less than usual as response scale). Higher values of all items indicate worse mental health. For each item in the GHQ-12, the participants were asked to rate the extent to which they have experienced a symptom during the last week. When the scoring scheme was bimodal (0-0-1-1), the sum score of GHQ-12 was ranged from 0 to 12 . Scoring 4 or more is indicated mental health problem. The GHQ-12 was validated in Iran [23].

\section{Assessment of quality of life}

QoL was measured by the WHO Quality of Life-brief version (WHOQOL-BREF), which is a 26-item selfadministered questionnaire with a 5-point Likert score format [44]. WHOQOL-BREF highlighted the multidimensional nature of QoL. The first two questions include perceived overall health and perceived overall QoL. The remaining 24 questions assess environmental (8 items), social (3 items), psychological (6 items), and physical (7 items) domains. The first two items on the global rating of QOL and perceived global health are not contained in mentioned four domains, so a sum of 26 items was used to make the overall QoL score. To easily compare 
the scores between domains, transformed domains and overall scores ranging from 4 to 20 were obtained from row scores (a simple summed score). Domain scores were calculated in a positive direction (higher scores indicate higher QoL). WHOQOL-BREF demonstrated good psychometric values in Iranian populations $[45,46]$.

\section{Statistical analysis}

Data were analyzed using the $\mathrm{R}$ statistical software version 3.6.2 (R Core Team, 2019). P-value $<0.05$ was considered statistically significant. Quantitative variables were summarized by the mean \pm standard deviation (SD), and qualitative variables were expressed as absolute frequencies (percentages). The independent two-sample t-test was used to compare the mean QoL score and its domains between dichotomous variables (gender, marital status, place of residence, categories of GHQ-12, and smoking status). In addition, we conducted the ANOVA test to determine the differences among polytomous variables, including age groups, education levels, and tertiles of physical activity. When data do not meet the parametric test assumptions, the Mann-Whitney $U$ and Kruskal-Wallis tests were used, respectively. The univariate associations between domains and overall scores of QoL and quantitative variables were tested by Pearson correlation (or Spearman correlation, if required). In addition, correlation coefficients of latent dimensions and individual GHQ-12's items were obtained from the Spearman correlation test.

In line with our study first objective, to evaluate the dimensionality or latent structure of GHQ-12, different competing exploratory MIRT models were fitted. MIRTs include a broad family of models, depending on the items' scale (ordinal, dichotomous, nominal, and so on). In the current analysis, twelve items of GHQ-12 were considered as ordinal variables with four response categories. An MGR model, as one of the MIRT models for ordered categorical items, was used to analyze the data via mirt package (version 1.32.1, April 2020) [32]. Moreover, the Oblimin rotation method was used to achieve more interpretable factors. Identified latent constructs were contained non-zero cross-loading items as an inherent issue in mental measurements [21]. It means that each item of GHQ-12 could be related to more than one latent construct. The extracted latent constructs were labeled and interpreted as mental health dimensions based on the majority of items loaded on, considering a loading $>=0.20$ for retention. Identified latent constructs as continuous variables quantify the extent to which an individual possesses mental health related to dimensions of GHQ-12.
The goodness of the fitted models was assessed by Root Mean Squared Error Approximation (RMSEA) with 90\% confidence interval (90\% CI), Standardized Root Mean Square Residuals (SRMSR), Comparative Fit Index (CFI), Bayesian Information Criterion (BIC), Akaike Information Criterion (AIC), Tucker-Lewis Index (TLI), corrected AIC (AICc), sample-Size Adjusted BIC (SABIC), and also chi-square $\left(x^{2}\right)$, related degree of freedoms (df), and Log-likelihood. In general, smaller values of AIC, BIC, AICc, SABIC, RMSEA, and SRMSR, as well as bigger values of TLI and CFI, usually show better fit models. The thresholds $\mathrm{RSMEA}<0.08, \mathrm{SRMR}<0.08$, CFI $\geq 0.95$, and TLI $\geq 0.95$ were considered model fit satisfactory [47]. In addition to goodness-of-fit indices, it has been suggested that the principle of parsimony (the lower number of parameters) and conceptual grounds to be considered for model selection [48]. The factor scores of the extracted domains of GHQ-12 derived from the best MGR model were computed, as the scores of mental health's dimensions, for using in the regression analysis.

To examine the simultaneous association between all QoL domains and extracted constructs of mental health, simple or multiple multivariate linear regression was performed. In these regression models, the QoL domains were treated as multivariate response variables, and each latent dimension of mental health was considered as the independent variable. Furthermore, simple or multiple univariate linear regression was used to evaluate the relationship between the QoL's overall score and each dimension of mental health. Crude and adjusted standardized along with unstandardized regression coefficients and 95\% CI as the associations' measures were presented. In adjusted regression models, the confounding effects of demographic variables, including age, sex, educational level, place of residence, and marital status, were considered in the first model. We further adjusted the confounding effects of lifestyle-related variables, including DQI, physical activity, smoking status, and adaptive and maladaptive coping strategies of stress in the second model. Additional adjustments were made for BMI in the final model.

\section{Results}

Table 2 presents descriptive characteristics of study participants.. $49.4 \%$ of participants were female. Mean \pm SD age of 1316 participants was $56.44 \pm 10.78$ years $(56.18 \pm 10.46$ in the female and $56.69 \pm 11.09$ in the male). Of the participants, $31.4 \%, 47.7 \%$, and $20.9 \%$ were $35-49$ years, $50-64$ years, and $\geq 65$ years old. The majority $(87.6 \%)$ of the participants were married, and about $82 \%$ were from urban areas. More details of demographic characteristics and lifestyle variables are shown in Table 2. 
Table 2 The demographic and life style futures of study participants and their association with domains and overall scores of quality of life

\begin{tabular}{|c|c|c|c|c|c|c|}
\hline & & \multicolumn{5}{|c|}{ Quality of life (QoL) } \\
\hline & & $\begin{array}{l}\text { Physical health } \\
\text { domain }\end{array}$ & $\begin{array}{l}\text { Psychological } \\
\text { domain }\end{array}$ & $\begin{array}{l}\text { Social } \\
\text { relationships } \\
\text { domain }\end{array}$ & $\begin{array}{l}\text { Environment } \\
\text { domain }\end{array}$ & Overall score \\
\hline Characteristics & Total & $15.28 \pm 2.92$ & $14.31 \pm 2.62$ & $15.02 \pm 3.19$ & $14.84 \pm 2.78$ & $14.80 \pm 2.43$ \\
\hline \multicolumn{7}{|l|}{ Age categories } \\
\hline 35-49 years & $413(31.4 \%)$ & $15.80 \pm 2.60$ & $14.28 \pm 2.44$ & $15.11 \pm 3.14$ & $14.87 \pm 2.61$ & $14.96 \pm 2.22$ \\
\hline 50-64 years & $628(47.7 \%)$ & $15.34 \pm 2.96$ & $14.36 \pm 2.65$ & $15.14 \pm 3.17$ & $14.91 \pm 2.81$ & $14.87 \pm 2.45$ \\
\hline$\geq 65$ years & 275 (20.9\%) & $14.38 \pm 3.08$ & $14.22 \pm 2.78$ & $14.61 \pm 3.3$ & $14.65 \pm 2.92$ & $14.43 \pm 2.63$ \\
\hline P-value ${ }^{1}$ & - & $<0.001$ & 0.8 & 0.03 & 0.33 & 0.009 \\
\hline \multicolumn{7}{|l|}{ Sex } \\
\hline Female & $650(49.4 \%)$ & $14.68 \pm 2.94$ & $13.82 \pm 2.55$ & $14.72 \pm 3.15$ & $14.63 \pm 2.77$ & $14.41 \pm 2.38$ \\
\hline Male & $666(50.6 \%)$ & $15.86 \pm 2.78$ & $14.78 \pm 2.59$ & $15.32 \pm 3.21$ & $15.04 \pm 2.77$ & $15.19 \pm 2.41$ \\
\hline P-value ${ }^{2}$ & - & $<0.001$ & $<0.001$ & 0.001 & 0.007 & $<0.001$ \\
\hline \multicolumn{7}{|l|}{ Marital status } \\
\hline Married & $1153(87.6 \%)$ & $15.45 \pm 2.85$ & $14.45 \pm 2.57$ & $15.16 \pm 3.13$ & $14.96 \pm 2.71$ & $14.95 \pm 2.38$ \\
\hline Single & 163 (12.4\%) & $14.08 \pm 3.14$ & $13.3 \pm 2.71$ & $14.06 \pm 3.46$ & $13.97 \pm 3.04$ & $13.78 \pm 2.54$ \\
\hline P-value ${ }^{2}$ & - & $<0.001$ & $<0.001$ & $<0.001$ & $<0.001$ & $<0.001$ \\
\hline \multicolumn{7}{|c|}{ Educational attainment years } \\
\hline $0-5$ years & $669(40.4 \%)$ & $14.49 \pm 2.94$ & $13.86 \pm 2.69$ & $14.47 \pm 3.19$ & $14.25 \pm 2.68$ & $14.22 \pm 2.42$ \\
\hline $6-12$ years & $456(34.7 \%)$ & $15.96 \pm 2.74$ & $14.64 \pm 2.47$ & $15.45 \pm 3.14$ & $15.38 \pm 2.75$ & $15.29 \pm 2.33$ \\
\hline$>12$ years & $191(14.5 \%)$ & $16.41 \pm 2.49$ & $15.07 \pm 2.4$ & $15.93 \pm 3$ & $15.65 \pm 2.72$ & $15.69 \pm 2.14$ \\
\hline P-value ${ }^{1}$ & - & $<0.001$ & $<0.001$ & $<0.001$ & $<0.001$ & $<0.001$ \\
\hline \multicolumn{7}{|l|}{ Place of residence } \\
\hline Urban & 1078 (81.9\%) & $15.36 \pm 2.91$ & $14.35 \pm 2.6$ & $15.06 \pm 3.2$ & $14.94 \pm 2.82$ & $14.86 \pm 2.44$ \\
\hline Rural & $238(18.1 \%)$ & $14.93 \pm 2.96$ & $14.11 \pm 2.69$ & $14.87 \pm 3.17$ & $14.41 \pm 2.52$ & $14.54 \pm 2.37$ \\
\hline P-value ${ }^{2}$ & - & 0.049 & 0.22 & 0.4 & 0.02 & 0.08 \\
\hline \multicolumn{7}{|l|}{ Smoking status } \\
\hline Ever & $182(14.2 \%)$ & $15.23 \pm 2.92$ & $14.28 \pm 2.56$ & $15.02 \pm 3.18$ & $14.83 \pm 2.78$ & $14.78 \pm 2.41$ \\
\hline Never & $1100(85.8 \%)$ & $15.71 \pm 2.85$ & $14.55 \pm 2.93$ & $15.02 \pm 3.36$ & $14.88 \pm 2.78$ & $14.99 \pm 2.47$ \\
\hline P-value ${ }^{2}$ & - & 0.04 & 0.051 & 0.81 & 0.67 & 0.18 \\
\hline \multicolumn{7}{|c|}{ Physical activity (METs-m/d) } \\
\hline Tertile $1(<480$ & $170.19 \pm 178.13$ & $15.27 \pm 3.32$ & $14.4 \pm 2.85$ & $15.27 \pm 3.47$ & $15.23 \pm 3.02$ & $14.97 \pm 2.68$ \\
\hline Tertile 2 (480-1680) & $1074.77 \pm 354.95$ & $15.36 \pm 2.78$ & $14.28 \pm 2.55$ & $15.04 \pm 3.1$ & $14.83 \pm 2.69$ & $14.82 \pm 2.39$ \\
\hline Tertile 3 (> 1680) & $4482.43 \pm 4205.32$ & $15.21 \pm 2.58$ & $14.22 \pm 2.4$ & $14.73 \pm 2.95$ & $14.43 \pm 2.51$ & $14.61 \pm 2.15$ \\
\hline P-value ${ }^{1}$ & - & 0.59 & 0.21 & 0.06 & $<0.001$ & 0.04 \\
\hline \multicolumn{7}{|l|}{ Categories of GHQ-12 } \\
\hline Normal (0-3) & $980(74.5 \%)$ & $15.77 \pm 2.72$ & $14.8 \pm 2.44$ & $15.46 \pm 3.02$ & $15.19 \pm 2.64$ & $15.24 \pm 2.26$ \\
\hline $\begin{array}{l}\text { Mental health prob- } \\
\text { lem (4-12) }\end{array}$ & $336(25.5 \%)$ & $13.84 \pm 3.01$ & $12.88 \pm 2.59$ & $13.74 \pm 3.34$ & $13.81 \pm 2.92$ & $13.53 \pm 2.45$ \\
\hline P-value ${ }^{2}$ & - & $<0.001$ & $<0.001$ & $<0.001$ & $<0.001$ & $<0.001$ \\
\hline Age (years) & $56.44 \pm 10.78$ & $-0.17^{4}$ & $-0.01^{4}$ & $-0.06^{4}$ & $-0.04^{4}$ & $-0.08^{4}$ \\
\hline P-value $e^{3}$ & - & $<0.001$ & 0.58 & 0.02 & 0.19 & 0.002 \\
\hline Body mass index & $27.87 \pm 4.53$ & $-0.09^{4}$ & $-0.06^{4}$ & $-0.08^{4}$ & $-0.05^{4}$ & $-0.07^{4}$ \\
\hline P-value ${ }^{3}$ & - & 0.001 & 0.046 & 0.006 & 0.10 & 0.008 \\
\hline Diet quality index & $0.69 \pm 0.26$ & $-0.08^{4}$ & $-0.13^{4}$ & $-0.08^{4}$ & $-0.15^{4}$ & $-0.14^{4}$ \\
\hline P-value & - & 0.004 & $<0.001$ & 0.006 & $<0.001$ & $<0.001$ \\
\hline $\begin{array}{l}\text { Adaptive coping } \\
\text { strategy }\end{array}$ & $42.54 \pm 31.74$ & $0.08^{4}$ & $0.11^{4}$ & $0.11^{4}$ & $0.05^{4}$ & $0.11^{4}$ \\
\hline P-value ${ }^{3}$ & - & 0.003 & $<0.001$ & $<0.001$ & 0.07 & $<0.001$ \\
\hline
\end{tabular}


Table 2 (continued)

\begin{tabular}{|c|c|c|c|c|c|c|}
\hline & & \multicolumn{5}{|c|}{ Quality of life (QoL) } \\
\hline & & $\begin{array}{l}\text { Physical health } \\
\text { domain }\end{array}$ & $\begin{array}{l}\text { Psychological } \\
\text { domain }\end{array}$ & $\begin{array}{l}\text { Social } \\
\text { relationships } \\
\text { domain }\end{array}$ & $\begin{array}{l}\text { Environment } \\
\text { domain }\end{array}$ & Overall score \\
\hline $\begin{array}{l}\text { Maladaptive coping } \\
\text { strategy }\end{array}$ & $38.65 \pm 38.27$ & $0.02^{4}$ & $0.02^{4}$ & $0.01^{4}$ & $-0.02^{4}$ & $0.01^{4} 0.01^{4}$ \\
\hline P-value ${ }^{3}$ & - & 0.48 & 0.56 & 0.83 & 0.5 & 0.73 \\
\hline Sum score of GHQ-12 & $2.33 \pm 3.12$ & $-0.33^{4}$ & $-0.36^{4}$ & $-0.27^{4}$ & $-0.25^{4}-0.25^{4}$ & $-0.36^{4}$ \\
\hline P-value $e^{3}$ & - & $<0.001$ & $<0.001$ & $<0.001$ & $<0.001$ & $<0.001$ \\
\hline
\end{tabular}

METs-m/d metabolic equivalent task minutes per day, GHQ General Health Questionnaire; Quantitative variables were expressed as Mean \pm SD; Qualitative variables were summarized as number (percentage); Superscripts 1, 2, and 3 indicate: $p$-values were obtained from ANOVA (or Kruskal Wallis test, if required), independent twosample t-test (or Mann-Whitney test, if required), and Pearson Correlation (or Spearman Correlation, if required), respectively. Superscript 4 reflects the correlation coefficient between each variable with overall and domains scores of $\mathrm{QoL}$

\section{The demographic and lifestyle futures of study participants and their association with domains and overall scores of quality of life}

The domains and overall scores of QoL at different levels of the demographic and life style features of study participants were shown in Table 2. The mean scores of the QoL domains (ranged 4-20) were; physical (15.28 \pm 2.92$)$, psychological (14.31 \pm 2.62$)$, environmental (14.84 \pm 2.78$)$, and social (15.02 \pm 3.19$)$. The mean QoL overall score (ranged 4-20) was $14.80 \pm 2.43$. 25.5\% of the current sample were reflected a high level of mental health problem based on scoring four or more of the GHQ sum score. The domains and overall mean scores of QoL were significantly lower in women, singles, people with lower levels of education, and higher levels of distress.

According to the correlational results represented in Table 2, we found out that a higher QoL overall score was associated with younger age, lower BMI, less mental health problem score, healthier diet quality, and a more adaptive coping strategy. More details of significant differences across demographic and lifestyle variables are shown in Table 2.

\section{Extraction of latent dimensions of mental health measured by GHQ-12}

Bar charts of the response distributions for positively and negatively phrased items of GHQ-12 were provided in Additional File 1: Fig. S1. Responses were given on a different four-point Likert scale for the negative and positive statement items. As shown in Additional File 1: Fig. S1, category 4 for every GHQ-12 item was reported by a minority of people, while the highest frequencies were obtained for category 2 (except for item 12). Graphs show the differential response patterning of positively and negatively worded items in the GHQ-12.
Table 3 presents the factor loadings of the fitted competing exploratory models for extracting the dimensions of mental health based on GHQ-12. In the present study, five different MGR models were specified and labeled based on the majority of items loaded on each factor and existing names from the literature. The competing models were as follows: (1) One-Dimensional model with 12 items loaded on one factor as mental health; (2) Bifactor model with one general factor as mental health and two additional uncorrelated factors (two specific factors) associated with negatively and positively phrased items for adjusting wording effects. In the Bifactor model, each item was influenced by both the general and specific factors. Specific factors cover the remaining common variance left after accounting for the general factor. It means that specific factors showed some features of negatively and positively phrased items that were not captured by the general factor. According to our model results, the general factor explained $39 \%$ of the common variance. However, $24 \%$ and $9 \%$ of the remaining shared variance were explained by positive and negative statement items, respectively. (3) Two-Dimensional model in which twelve items were loaded on two constructs. In the exploratory model, six negative statement items were loaded on one factor, and six positive statement items were loaded on another construct; (4) Three-Dimensional model with considering three latent constructs of twelve items; and finally, Four-Dimensional model in which the six negatively phrased items constructed the first two factors (F1 and F2), whereas the other two factors (F3 and F4) are made up of the six positive statement items. In the model, items 10 (across F1 and F2), 2 and 3 (across F3 and F4) were cross-loading items. The last three mentioned models were correlated trait MGR models in which extracted factors were correlated together.

The results of the goodness of fit indices for the five models compared are presented in Table 4 . The 


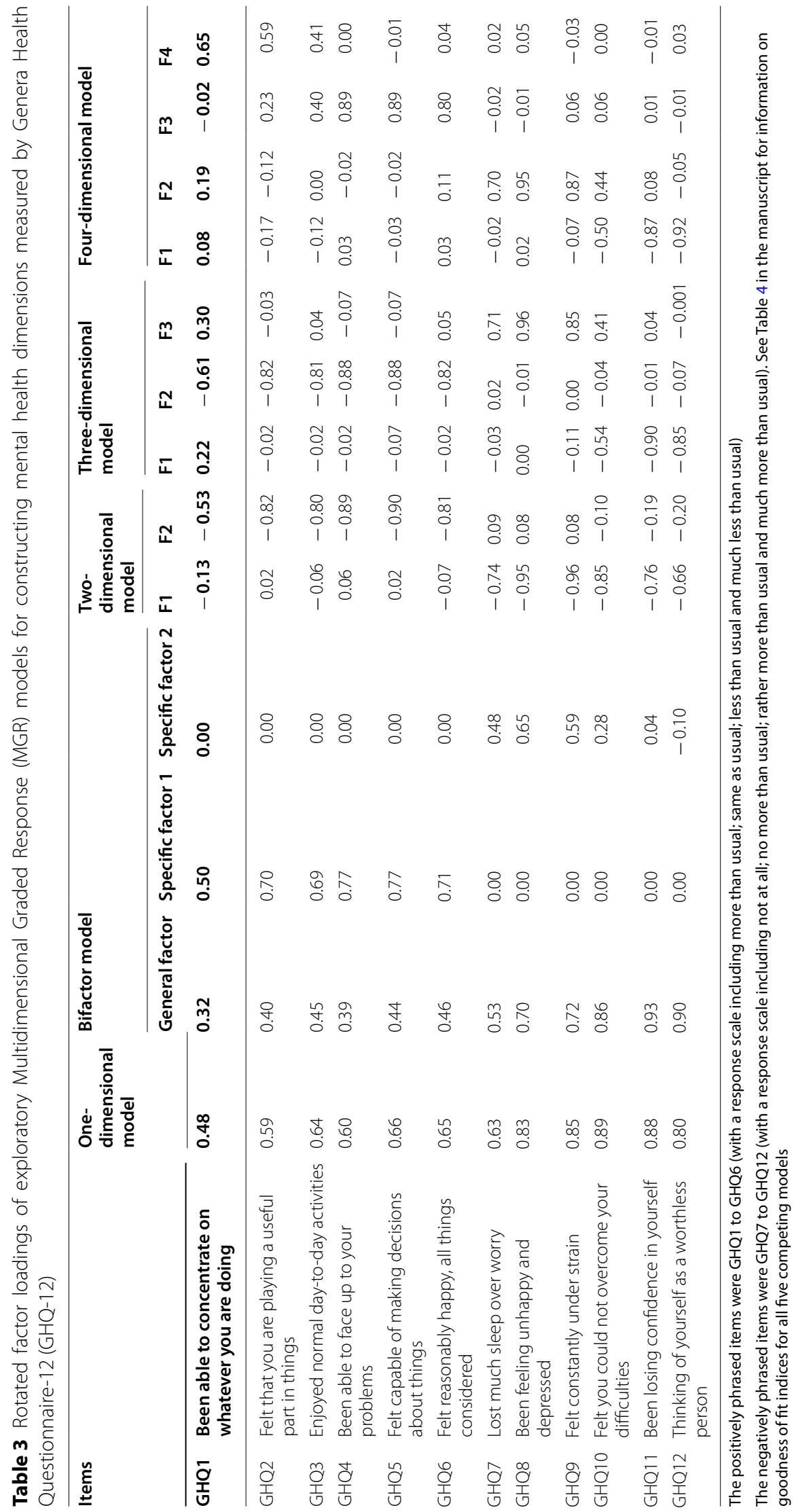


One-Dimensional model had a worst fit than other competing models. However, wording effects adjustment in the One-Dimensional model (as the Bifactor model) considerably improved the goodness of fit indices. The best the goodness of fit indices belonged to ThreeDimensional model with $\mathrm{SRMR}=0.033, \mathrm{CFI}=0.996$, $\mathrm{TLI}=0.979$ and RMSEA $=0.051$ (95\% CI $0.036,0.068$ ), and Four-Dimensional model with $\mathrm{SRMR}=0.028$, $\mathrm{CFI}=0.994, \mathrm{TLI}=0.984$, and $\mathrm{RMSEA}=0.051(95 \% \mathrm{CI}$ $0.042,0.061$ ) in our data. According to fit indices, these two best models were not greatly distinguishable. Therefore, the Three-Dimensional model was considered as the best fitted model in our data due to more parsimonious specifications and more interpretable factors.

In Table 3, the first latent construct (F1), namely Self Confidence (SC) of the Three-Dimensional model, as the best MGR model, was characterized by items 1,10 , 11, and 12 from GHQ-12. The second latent construct, labeled as Social Function (SF), contained items 1 to 6 (positively worded items). The third one, named Anxiety/ Depression (A/D), was considerably loaded with items $1,7,8,9$, and 10. As shown in Table 3, items 1 and 10 were cross-loading items and loaded on multiple underlying constructs. Item 1 was loaded on all constructs, while item 10 was loaded on the dimensions of SC and A/D. Moreover, the correlation between the dimensions of SC and SF was 0.67 , between the dimensions of SC and $\mathrm{A} / \mathrm{D}$ was -0.89 , and also between the dimensions of SF and $\mathrm{A} / \mathrm{D}$ was -0.51 . Furthermore, Cronbach's alpha coefficients were obtained between 0.76 and 0.85 for three latent constructs of the Three-Dimensional model. Figure 1 showed graphical presentation of the Three-Dimensional model, as the best MGR model, for GHQ-12 in the current study.

Mean and 95\% CI of latent constructs of mental health based on Three-Dimensional model were presented across their constituent items using Error-Bar charts in Additional File 1: Fig. S2. Furthermore, Additional File 1: Fig. S2 graphically depicts the mean and 95\% CI of three latent dimensions across sum score of GHQ (ranged 0 to
12). Lower values of all twelve items and the sum score of GHQ reflect better mental health and vice versa. Higher values of the SC and SF dimensions indicate the lower intensity of mental health, while higher scores of the A/D reflect more elevated mental health. As shown in Additional File 1: Fig. S2, the intensity of mental health dimensions was different across various levels of GHQ sum scores, in particular with scoring four or more as high distress level.

Furthermore, the correlation coefficients between GHQ-12's latent dimensions and domains of QOL were presented in Additional File 1: Table S1. Significant negative correlations between all domains of $\mathrm{QOL}$ and the $\mathrm{A} / \mathrm{D}$ dimension of mental health revealed an acceptable divergent Validity. In addition, SC and SF dimensions of mental health had moderate positive correlations with all domains of the QOL, ranging from 0.24 to 0.39 $(\mathrm{p}<0.001)$, indicating satisfactory convergent validity based on association analysis with QOL.

Moreover, we evaluated the discriminant validity of newly extracted domains of mental health internally (Additional File 1: Table S1). Findings of item-scale correlations (with overlap correction) showed a higher correlation between each item with its related factor. Moreover, a lower correlation was found between each item with other factors.

\section{The relationship between latent dimensions of mental health and quality of life domains}

Table 5 shows the results of crude and adjusted regression models of the relationships between domains of QoL with dimensions of mental health, and the sum score of GHQ. In the crude model, we reached significant positive associations of SC and SF dimensions of mental health with all aspects of QoL. Furthermore, higher scores of the A/D dimension (worse psychological health) were associated with lower scores of all aspects and the overall QoL. The mentioned associations of mental health dimensions in later models were slightly changed by

Table 4 Model fit indices for all five competing exploratory Multidimensional Graded Response (MGR) models

\begin{tabular}{llllllllllll}
\hline MGR Model & $\chi^{2}$ & df & RMSEA (90\% Cl) & SRMSR & TLI & CFI & Log-likelihood & AIC & AICC & BIC & SABIC \\
\hline 1 & 193.40 & 30 & $0.064(0.056,0.073)$ & 0.157 & 0.967 & 0.977 & $-13,033.42$ & $26,162.85$ & $26,166.56$ & $26,411.6$ & $26,259.13$ \\
2 & 100.46 & 18 & $0.059(0.048,0.071)$ & 0.036 & 0.972 & 0.988 & $-11,829.06$ & $23,778.11$ & $23,783.95$ & $24,089.05$ & $23,898.46$ \\
3 & 66.87 & 19 & $0.044(0.033,0.055)$ & 0.046 & 0.985 & 0.993 & $-12,006.31$ & $24,130.63$ & $24,136.27$ & $24,436.39$ & $24,248.97$ \\
4 & 40.27 & 9 & $0.051(0.036,0.068)$ & 0.033 & 0.979 & 0.996 & $-11,886.86$ & $23,911.72$ & $23,919.47$ & $24,269.3$ & $24,050.12$ \\
5 & 107.13 & 24 & $0.051(0.042,0.061)$ & 0.028 & 0.984 & 0.994 & $-11,826$ & $23,807.99$ & $23,817.95$ & $24,212.21$ & $23,964.44$ \\
\hline
\end{tabular}

$d f$ degree of freedom, RMSEA root mean squared error approximation, Cl confidence interval, SRMSR Standardized Root Mean Square Residuals, TLITucker-Lewis Index, CFI Comparative Fit Index, AIC Akaike Information Criterion, BIC Bayesian Information Criterion, AICC corrected AIC, SABIC sample-Size Adjusted BIC; Model 1: one-dimensional model; Model 2: Bifactor model; Model3: two-dimensional model; Model 4: three-dimensional model; Model 5: four-dimensional model 


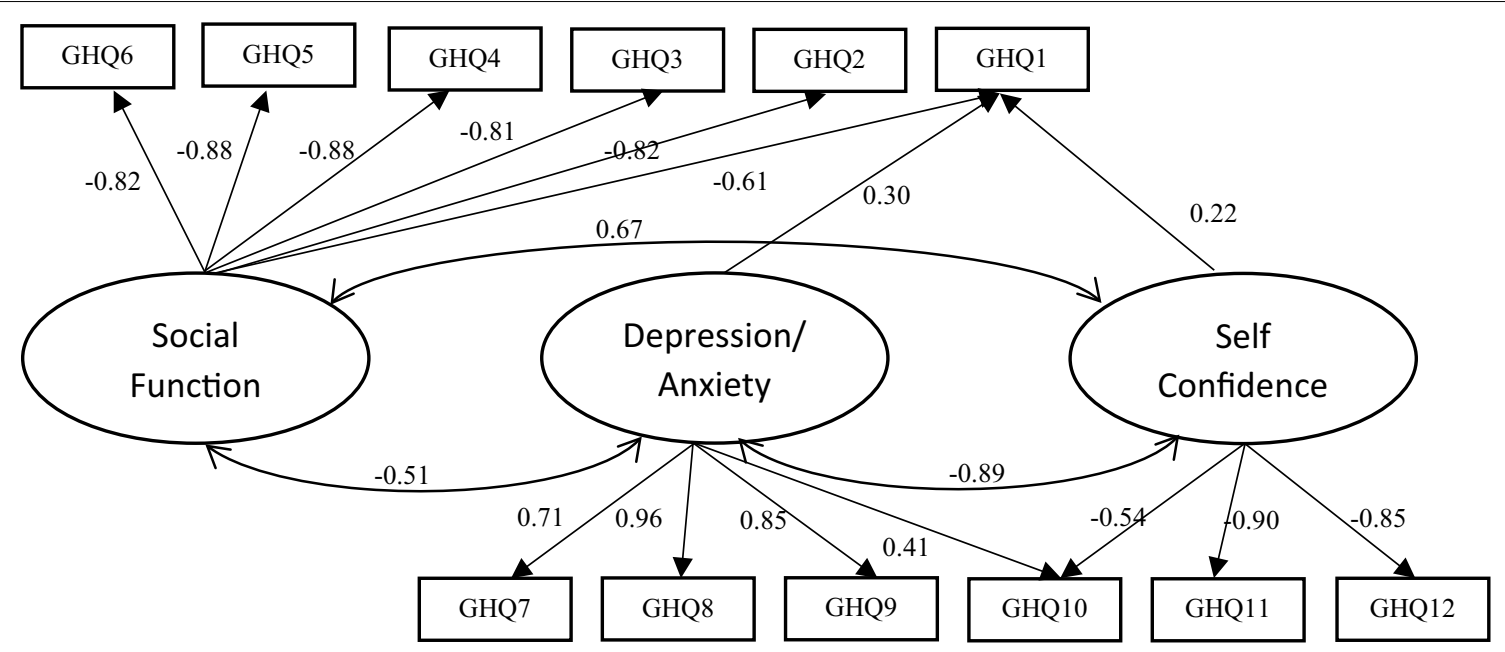

$\begin{array}{ll}\text { GHQ1 } & \text { Been able to concentrate on whatever you are doing } \\ \text { GHQ2 } & \text { Felt that you are playing a useful part in things } \\ \text { GHQ3 } & \text { Enjoyed normal day-to-day activities } \\ \text { GHQ4 } & \text { Been able to face up to your problems } \\ \text { GHQ5 } & \text { Felt capable of making decisions about things } \\ \text { GHQ6 } & \text { Felt reasonably happy, all things considered }\end{array}$

GHQ1 Been able to concentrate on whatever you are doing

GHQ2 Felt that you are playing a useful part in things

GHQ6 Felt reasonably happy, all things considered

\begin{abstract}
GHQ7 Lost much sleep over worry
GHQ8 Been feeling unhappy and depressed

GHQ9 Felt constantly under strain

GHQ10 Felt you could not overcome your difficulties

GHQ11 Been losing confidence in yourself

GHQ12 Thinking of yourself as a worthless person
\end{abstract}

Fig. 1 Graphical presentation of three-dimensional graded response model for 12-item General Health Questionnaire in the present study

further adjustment for other confounders, but these associations remained enormously significant.

In the full adjusted model, a one-unit increase in SC dimension was associated with 1.05-, 1.04-, 1.02-, 0.89-, and 0.98-unit increase in the mean scores of physical health, psychological, social relationships, environment domains, and overall score of QoL, respectively. Furthermore, standardized coefficients suggested that a one-SD increase in SC dimension was associated with $43 \%, 48 \%$, $38 \%, 39 \%$, and $49 \%$-SD increase in physical health, psychological, social relationships, environment domains and the overall scores of QoL, respectively.

Likewise, after adjusting for confounding variables, a one-SD increase in SF dimension increased the scores of physical health, psychological, social relationships, environment domains, and the overall QoL by more than one-quarter of an SD. Similar to the SC dimension of mental health, the highest to the lowest standardized coefficients of the SF dimension were respectively related to the psychological, physical health, social relationships, and environmental condition domains.

On the contrary, in the full adjusted model, oneSD increase in score of A/D dimension can lead to SD decline of $38 \%, 40 \%, 31 \%, 29 \%$, and $40 \%$ in scores of physical health domain, psychological domain, social relationships domain, environment domain and the overall QoL respectively. Likewise, SD decrease of sum score of GHQ was $31 \%, 35 \%, 27 \%, 24 \%$, and $34 \%$, respectively. For the
A/D dimension, the psychological domain of QoL had the highest standardized coefficient of association, while the lowest standardized coefficient of the association was found for the environmental condition domain. More details on the relationship between QoL domains with mental health dimensions in other adjusted models can be found in Table 5 . Figure 2 graphically depicts the full adjusted unstandardized coefficients and $95 \%$ CI of the relationships between dimensions of mental health and QOL domains.

\section{Discussion}

In this study, we explored the latent structures of GHQ12 as dimensions of mental health within the MGR model framework as a powerful modeling approach evaluating questionnaires with ordered Likert format responses [31] in a large population-based study in Isfahan, Iran. In this regard, we compared five competing exploratory models, including (1) One-Dimensional model with all GHQ-12 items loaded on one latent construct as mental health, (2) Bifactor model with one general factor as mental health, and two specific factors for considering the role of wording effects associated with negatively and positively phrased items; (3) Two-Dimensional model in which six negative statement items were loaded on one factor and six positive statement items were loaded on another construct, (4) Three-Dimensional model identifying three latent 


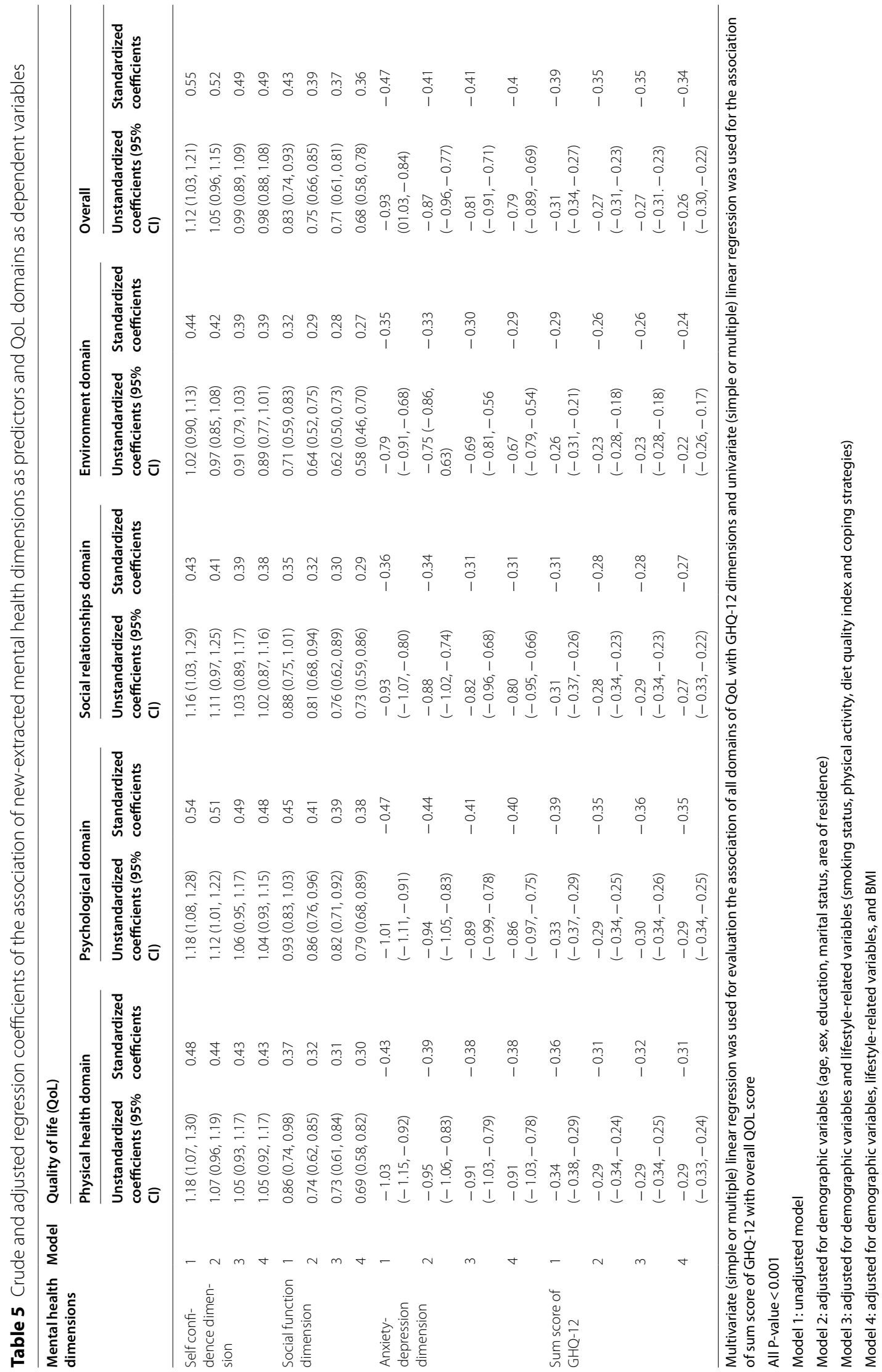


Self Confidence Dimension of Mental Health

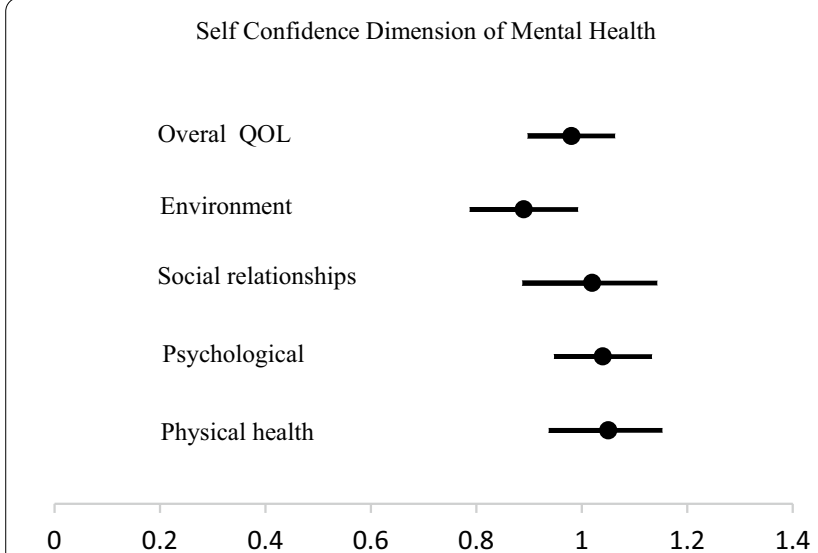

Anxiety/Depression Dimension of Mental Health

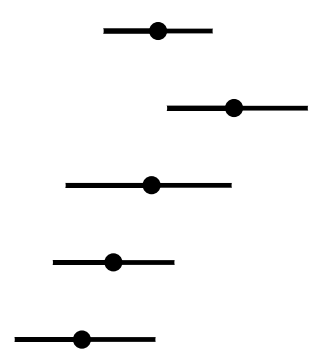

Overal QOL

Environment

Social relationships

Psychological

Physical health
Social Function Dimension of Mental Health

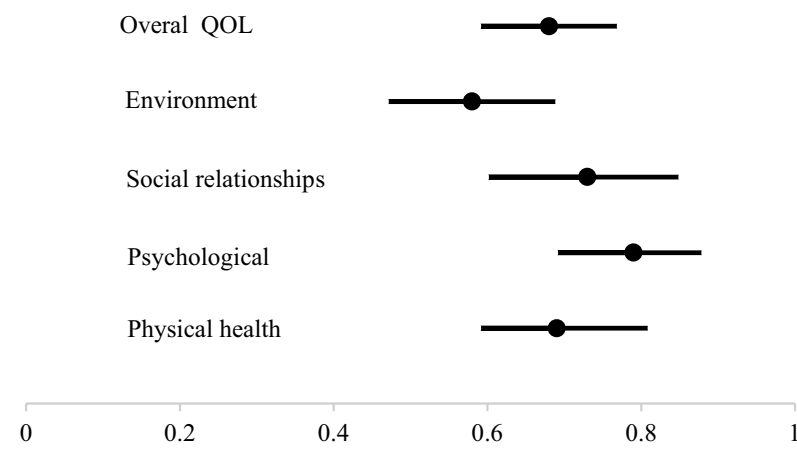

Sum score of GHQ-12

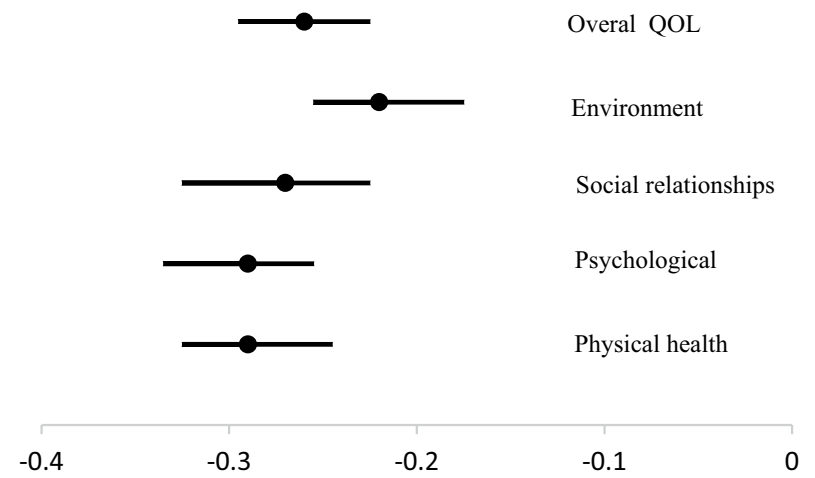

Fig. 2 The points in the lines and upper and lower limits depict the adjusted regression coefficients and $95 \%$ confidence interval of relationships between dimensions of mental health and quality of life domains

constructs of SC (items 1, 10-12), SF (items 1-6), and A/D (items 1, 7-10); and finally, Four-Dimensional model in which the six negatively phrased items constructed the first two factors, whereas the other two factors are made up of the six positive statement items. In the models under consideration, cross-loading items in each identified construct and the paired correlation between latent constructs in each model were considered. Furthermore, after selecting the best-fitted model, we examined how different aspects of QoL, including physical health, psychological, social relationships, environment domains, are associated with latent dimensions of mental health in the general population.

Our findings of the current study showed One-Dimensional model had a worst fit than the alternative models. In agreement with our results, many studies are available in favor of the multidimensional compared to the unidimensional structure of GHQ-12 around the world among various populations such as the employee population
[17], diseases-specific populations [28, 49], and adolescents and general populations [16, 22, 50].

Moreover, in disagreement with some studies [14, 16-18], findings of the present study showed although the unidimensional model with adjusting wording effects associated with negatively and positively phrased items considerably improved fit indices compared to the OneDimensional model, it did not give a suitable fit compared to Three and Four-Dimension models in our population. Following these findings in our study, similar results were observed in some studies [50]. In the current study, although the Four-Dimensional model gave suitable fit indices, the best model for GHQ-12 latent structures was considered the Three-Dimensional model based on the balance of better fit indices, more parsimonious estimation, and more interpretable latent dimensions.

Regardless of the consideration of the ordinal nature of response categories in the parameter estimation method and non-zero cross-loading items of GHQ-12, some previous studies are in favor of the Three-Dimensional 
model. In this regard, a recent cross-sectional study from the Al Kharj population in Saudi Arabia identified three factors of GHQ-12, including social dysfunction (items $1-6$ ), anxiety (items 7-10), and loss of confidence (items 11-12) using CFA among people aged 18 years and older [20]. In addition, in another study among the general Spanish population aged between 25 and 65 years, a three-factor structure of GHQ-12 was proposed using EFA with cross-loading items but ignoring the ordinal nature of items. They used different names from those used by the current study. Identified three factors, namely Successful Coping (items 1-6), Self-esteem (items 8, 10-12), and Stress (items 7-9), were similar to ours with small differences in the cross-loading items [19]. Furthermore, the Three-Dimensional model also provided a superior fitted level in other previous studies, including Finnish working-age subjects between 25 and 59 years old [22], 58-72 years French adults [26], and clinical cases in Singapore [28].

In contrast with our findings, some studies among the Iranian population in other areas of the country have achieved different latent structures of GHQ-12 among young people aged 18 to 25 years old [23], university students [24], and the elderly population [25]. Findings of the recent study of Northern Iran on participants aged ten years and older revealed the model with the best fit was one-dimensional model adjusting negative statement items effect, followed by the three-dimensional model (social dysfunction (items 1-6), A/D (items 7-10), and loss of confidence (items 11-12)) [16]. In this regard, it was suggested that the underlying latent structure might depend on the population under study [18].

Taken together, some of the inconsistencies of GHQ12 's factor structure in related studies might be because of the participant's levels of distress [18]; response bias to positive and, or negative statement items [14]; different parameter estimation approaches used [30]; multiple schemes for scoring the GHQ-12s items [29]; various latent variable modeling for assessing latent constructs such as CFA, EFA, IRT, and SEM; differential item functioning due to individual differences, in particular gender- and age-related differential item functioning [17, 49]; misinterpretation of items in the specific negative statement due to the different level of participants education; with/without considering non-zero cross-loadings; and diverse populations under consideration.

Furthermore, in the second objective of the current study, we examined the associations of identified latent mental health dimensions with all QoL aspects. After adjusting for age, sex, education, marital status, area of residence, smoking status, physical activity, diet quality index, coping strategies, and BMI, we reached significant positive associations of SC and SF dimensions of mental health with all QoL aspects. In other word, a one-SD increase in dimensions of SC and SF was associated with a 38 - to $48 \%$-SD and 27 - to $38 \%$-SD increase in the domains scores of QoL, respectively. Furthermore, the present study showed higher scores of A/D dimension (worse psychological health) were associated with lower scores of all aspects of QoL. In other word, for each one-SD increase in score of $\mathrm{A} / \mathrm{D}$ dimension, the domains scores of QoL decreased by 29- to 40\%-SD. The highest to the lowest standardized coefficients for all latent mental health dimensions were respectively related to the psychological, physical health, social relationships, and environmental condition domains of QoL. It means that the psychological aspect of QoL is the most affected by all latent mental health dimensions, followed by physical health, social relationships, and environmental condition domains.

Limited studies have focused on the association of latent structures of mental health and QoL domains. Regardless of latent or obvious structures of assessments, simple or advanced statistical analysis, evaluating separate or simultaneous relationships, and underlying instruments under consideration, our findings conform with previous research supporting that QoL domains are highly associated with the mental health levels among general and specific populations [3-11].

In line with our findings, a cross-sectional study with a small sample size of outpatients with depression and, or anxiety disorders in Singapore showed that the three latent factors of GHQ-12, named social dysfunction (items 1-6), anxiety and depression (items 7-10), and loss of confidence (items 11-12) gave the best fit levels using CFA. They found that diminished all health-related QoL domains (measured by Short Form 36 Health Survey (SF-36)) were considerably associated with three latent factors of mental health. This study, using simple statistical analysis, showed that social dysfunction, anxiety and depression, and loss of confidence were negatively correlated with physical functioning, general health, bodily pain, mental health, social functioning, role limitations due to physical problems, vitality, and role limitations due to emotional problems. In disagreement with our findings, they found that correlation coefficients of three latent factors of mental health were in the neighborhood of 0.83 to 0.90 , which it may be difficult to distinguish them [28].

In previous studies, the close link between mental disorders, including depression and anxiety, and almost all QoL domains, as measured by WHOQOL-BREF, are well established [3, 6, 10, 33]. It was shown that reduced QOL was considerably associated with even low levels of depression and anxiety symptoms [3]. A cross-sectional study on primary care patients with common mental 
disorders (such as depression and anxiety) found out that symptom intensity and comorbidity were significantly associated with a decrease in various aspects of QoL, especially the psychological and physical domains [33]. In line with our results, a cross-national study in six European countries showed that mental disorders have the most impact on the psychological than the physical domain of QoL [34]. Moreover, given the marked significant and independent relationships between latent dimensions of mental health and the social and environmental domains of QoL in the current study, it seems that in an attempt to full recovery as assessed by improved QoL outcomes, treatment of clinical symptoms may not be sufficient, as concluded in previous studies [33]. Several potential mechanisms explain the loss of different aspects of QoL due to dimensions of mental health. Impairments and limitations in cognitive, emotional, and motivational function caused by mental health problems may lead to disability and loss of quality of life [34].

This study is one of the first studies which has simultaneously investigated the association between all domains of QoL and latent dimensions of mental health identified by the MGR model in a representative sample of the general population. Our findings have some limitations and strengths. The current study considered the real nature of items assessing latent structure using a reliable statistical method. We believe that the family of Item Response Theory models can help to improve the quality of developing instruments. However, identifying the latent structure of mental health with considering individual differences is suggested in future studies.

Moreover, future researches may benefit from taking into account extreme response style (systematic tendency to choose extreme or middle options in Likert-type or rating scale items) in latent structures [51]. Because of the cross-sectional nature of the current study, causality and directionality of the effects cannot be determined. However, a large and representative sample in the current study enables us to have adequate power to interpret our results. Also, we used the complete-case method to handle missing data, so more advanced approaches such as multiple imputations are recommended in future studies. Further research would be valuable to consider some likely confounders/mediators such as personality traits, social support, and life stressors which were not in our adjusted models.

\section{Conclusions}

GHQ-12 is a useful screening instrument for mental health status in the community and primary care settings worldwide due to the brevity and easiness of administration and comprehensibility. The current study identified three correlated yet different latent dimensions of GHQ-12, named SF, assessing psychological health; SC, indicating individual's relationship to himself/herself; and A/D, reflecting psychological disorders using the advanced statistical analysis by focusing on tackling the parameter estimation challenges. Our findings confirm that the GHQ-12 as a multidimensional rather than unitary instrument measures distinct mental health aspects. Furthermore, we appropriately found that all aspects of QoL declined when the intensity of A/D dimensions increased. On the contrary, higher scores of SF and SC dimensions were associated with improved all aspects of QoL. Moreover, the psychological aspect of QoL is the most affected by all latent mental health dimensions, followed by physical health, social relationships, and environmental condition domains. Besides, given the marked significant and independent associations between latent dimensions of mental health and the social and environmental domains of QoL in the current study, it seems that in an attempt to full recovery as assessed by improved QoL outcomes, treatment of clinical symptoms may not be sufficient.

In future studies to establish and distinguish the clinical benefits of mental health dimensions, it is suggested to compare the factor scores in different groups of chronic somatic conditions and mental diseases. Identifying and differentiating the mental health structures in each community and implementing intervention programs focused on specific dimensions may help prevent further deterioration and improve QoL. Other researches are needed to confirm our findings by focusing on overcoming our limitations.

\section{Abbreviations \\ QoL: Quality of life; WHO: World Health Organization; GHQ: General Health Questionnaire; EFA: Exploratory factor analysis; CFA: Confirmatory factor analy- sis; SEM: Structure equation model; MGR: Multidimensional Graded Response; MIRT: Multidimensional Item Response Theory; ICS: Isfahan Cohort Study; ICS2: Isfahan Cohort Study 2; BMI: Body mass index; MET-m/d: Metabolic equivalent task minutes per day; IPAQ: International Physical Activity Questionnaire; FFQ: Food frequency questionnaire; DQI: Diet quality index; WHOQOL-BREF: WHO Quality of Life-brief version; SD: Standard deviation; RMSEA: Root mean squared error approximation; CI: Confidence interval; SRMSR: Standardized Root Mean Square Residuals; TLI: Tucker-Lewis Index; CFI: Comparative Fit Index; AIC: Akaike Information Criterion; BIC: Bayesian Information Criterion; AICc: Corrected AIC; SABIC: Sample-Size Adjusted BIC; $x^{2}$ : Chi-square; df: Degree of freedoms; SC: Self confidence; SF: Social function; A/D: Anxiety/ depression; SF-36: Short Form 36 Health Survey.}

\section{Supplementary Information}

The online version contains supplementary material available at https://doi. org/10.1186/s12955-021-01892-9.

Additional file 1. Additional data about items of GHQ-12 and its newly explored domains. 


\section{Acknowledgements}

We would like to acknowledge the ICS staff, collaborators, and participants for their contributions.

\section{Authors' contributions}

FN and AF conducted data analysis and prepared the manuscript draft. HR MS, and NS contributed to the conception, study design, supervision, project administration of ICS2 and revision the manuscript. AF supervised the current secondary study in the framework of PhD thesis in Biostatistics and critically revised the manuscript. All authors have given final approval of the version to be published and agree to be accountable for all aspects of the work. All authors read and approved the final manuscript.

\section{Funding}

The current study is based on a Ph.D. thesis in Biostatistics approved ethically by Isfahan University of Medical Sciences with research ethic Code: IR.MUI. RESEARCH.REC. 1398.421 and Scientific Research Project Number: 398590. The analyzed data were obtained from the ICS2 study with scientific research project number: 93114 . The current research in the framework of ICS2 did not receive any financial support.

\section{Availability of data and materials}

The data sets used and, or analyzed during the current study are available from the corresponding author on reasonable request.

\section{Declarations}

\section{Ethics approval and consent to participate}

The study was approved by the Ethics Committee of Isfahan Cardiovascular Research Center, a World Health Organization-collaborating center. All participants provided written informed consent to participate in the study.

\section{Consent for publication}

Not applicable.

\section{Competing interests}

The authors declare that they have no competing interests.

\section{Author details}

${ }^{1}$ Student Research Committee, School of Health, Isfahan University of Medical Sciences, Isfahan, Iran. ${ }^{2}$ Department of Biostatistics and Epidemiology, School of Health, Isfahan University of Medical Sciences, Hezar Jerib Street, 8174673461 Isfahan, Iran. ${ }^{3}$ Isfahan Cardiovascular Research Center, Cardiovascular Research Institute, Isfahan University of Medical Sciences, Isfahan, Iran. ${ }^{4}$ Cardiac Rehabilitation Research Center, Cardiovascular Research Institute, Isfahan University of Medical Sciences, Isfahan, Iran. ${ }^{5}$ Heart Failure Research Center, Cardiovascular Research Institute, Isfahan University of Medical Sciences, Isfahan, Iran.

\section{Received: 18 March 2021 Accepted: 2 November 2021}

Published online: 14 November 2021

\section{References}

1. Katschnig $H$, Krautgartner M. Quality of life: a new dimension in mental health care. Psychiatry Soc. 2002;66:171-92.

2. Group W. The World Health Organization quality of life assessment (WHOQOL): position paper from the World Health Organization. Soc Sci Med. 1995;41:1403-9.

3. Chachamovich JL, Chachamovich E, Ezer H, et al. Psychological distress as predictor of quality of life in men experiencing infertility: a cross-sectional survey. Reprod Health. 2010;7:3.

4. Fellinger J, Holzinger D, Dobner $U$, et al. Mental distress and quality of life in a deaf population. Soc Psychiatry Psychiatr Epidemiol. 2005;40:737-42.

5. Leiler A, Bjärtå A, Ekdahl J, et al. Mental health and quality of life among asylum seekers and refugees living in refugee housing facilities in Sweden. Soc Psychiatry Psychiatr Epidemiol. 2019;54:543-51.

6. Ohaeri JU, Awadalla AW, Gado OM. Subjective quality of life in a nationwide sample of Kuwaiti subjects using the short version of the
WHO quality of life instrument. Soc Psychiatry Psychiatr Epidemiol. 2009;44:693-701.

7. Okyay P, Atasoylu G, Mete Ö, et al. How is quality of life affected in women in the presence of anxiety and depression symptoms? Turk Psikiyatri Dergisi. 2012;23:178.

8. Olatunji BO, Cisler JM, Tolin DF. Quality of life in the anxiety disorders: a meta-analytic review. Clin Psychol Rev. 2007;27:572-81.

9. Parsaei R, Roohafza H, Feizi A, et al. Quality of life and common psychological problems profile in a large sample of manufacturing employees in a developing country: an association analysis using latent class regression. Alexand J Med. 2019;55:37-43.

10. Rusli BN, Edimansyah BA, Naing L. Working conditions, self-perceived stress, anxiety, depression and quality of life: a structural equation modelling approach. BMC Public Health. 2008;8:48.

11. Serrano-Aguilar P, Ramallo-Farina Y, Trujillo-Martín MDM, et al. The relationship among mental health status (GHQ-12), health related quality of life (EQ-5D) and health-state utilities in a general population. Epidemiol Psichiatr Soc. 2009;18:229-39.

12. Organization WH. Mental health around the world: stop exclusion, dare to care: World Health Day 2001. World Health Organization. 2000.

13. Goldberg DP, Gater R, Sartorius N, et al. The validity of two versions of the GHQ in the WHO study of mental illness in general health care. Psychol Med. 1997;27:191-7.

14. Gnambs T, Staufenbiel T. The structure of the General Health Questionnaire (GHQ-12): two meta-analytic factor analyses. Health Psychol Rev. 2018;12:179-94.

15. Hankins $M$. The reliability of the twelve-item general health questionnaire (GHQ-12) under realistic assumptions. BMC Public Health. 2008;8:1-7.

16. Motamed N, Zakeri SE, Rabiee B, et al. The factor structure of the twelve items general health questionnaire (GHQ-12): a population based study. Appl Res Qual Life. 2018;13:303-16.

17. Rodrigo MF, Molina JG, Losilla J-M, et al. Method effects associated with negatively and positively worded items on the 12-item General Health Questionnaire (GHQ-12): results from a cross-sectional survey with a representative sample of Catalonian workers. BMJ open. 2019;9:e031859.

18. Smith AB, Oluboyede $Y$, West $R$, et al. The factor structure of the GHQ-12: the interaction between item phrasing, variance and levels of distress. Qual Life Res. 2013;22:145-52.

19. del Pilar S-López M, Dresch V. The 12-Item General Health Questionnaire (GHQ-12): reliability, external validity and factor structure in the Spanish population. Psicothema. 2008;20:839-43.

20. El-Metwally A, Javed S, Razzak HA, et al. The factor structure of the general health questionnaire (GHQ12) in Saudi Arabia. BMC Health Serv Res. 2018:18:595.

21. Griffith GJ, Jones K. Understanding the population structure of the GHQ12: Methodological considerations in dimensionally complex measurement outcomes. Soc Sci Med. 2019;243:112638.

22. Mäkikangas A, Feldt T, Kinnunen U, et al. The factor structure and factorial invariance of the 12-item General Health Questionnaire (GHQ-12) across time: evidence from two community-based samples. Psychol Assess. 2006:18:444-51.

23. Montazeri A, Harirchi AM, Shariati M, et al. The 12-item General Health Questionnaire (GHQ-12): translation and validation study of the Iranian version. Health Qual Life Outcomes. 2003;1:66.

24. Najarkolaei FR, Raiisi F, Rahnama P, et al. Factor structure of the Iranian version of 12-item general health questionnaire. Iran Red Crescent Med J. 2014;16:e11794.

25. Namjoo S, Shaghaghi A, Sarbaksh P, et al. Psychometric properties of the General Health Questionnaire (GHQ-12) to be applied for the Iranian elder population. Aging Ment Health. 2017;21:1047-51.

26. Salama-Younes $M$, Montazeri A, Ismail $A$, et al. Factor structure and internal consistency of the 12-item General Health Questionnaire (GHQ-12) and the Subjective Vitality Scale (VS), and the relationship between them: a study from France. Health Qual Life Outcomes. 2009;7:1-6.

27. Liang $Y$, Wang $L$, Yin $X$. The factor structure of the 12-item general health questionnaire (GHQ-12) in young Chinese civil servants. Health Qual Life Outcomes. 2016;14:1-9. 
28. Gao F, Luo N, Thumboo J, et al. Does the 12-item General Health Questionnaire contain multiple factors and do we need them? Health Qual Life Outcomes. 2004;2:63.

29. Alexandrowicz RW, Friedrich F, Jahn R, et al. Using Rasch-models to compare the 30-, 20-, and 12-items version of the general health questionnaire taking four recoding schemes into account. Neuropsychiatrie. 2015;29:179-91.

30. Wang WC, Cunningham EG. Comparison of alternative estimation methods in confirmatory factor analyses of the General Health Questionnaire. Psychol Rep. 2005;97:3-10.

31. Depaoli S, Tiemensma J, Felt JM. Assessment of health surveys: fitting a multidimensional graded response model. Psychol Heal Med. 2018;23:1299-317.

32. Chalmers RP. mirt: a multidimensional item response theory package for the R environment. J Stat Softw. 2012;48:1-29.

33. González-Blanch C, Hernández-de-Hita F, Muñoz-Navarro R, et al. The association between different domains of quality of life and symptoms in primary care patients with emotional disorders. Sci Rep. 2018;8:1-10.

34. Investigators EM, Alonso J, Angermeyer M, et al. Disability and quality of life impact of mental disorders in Europe: results from the European Study of the Epidemiology of Mental Disorders (ESEMeD) project. Acta Psychiatr Scand. 2004;109:38-46.

35. Parsaei R, Roohafza $H$, Feizi $A$, et al. How different stressors affect quality of life: an application of multilevel latent class analysis on a large sample of industrial employees. Risk Manag Healthc Policy. 2020;13:1261.

36. Sarrafzadegan N, Talaei M, Sadeghi M, et al. The Isfahan cohort study: rationale, methods and main findings. J Hum Hypertens. 2011;25:545-53.

37. Sarrafzadegan N, Hassannejad R, Roohafza H, et al. A 10-year Isfahan cohort on cardiovascular disease as a master plan for a multi-generation non-communicable disease longitudinal study: methodology and challenges. J Hum Hypertens. 2019;33:807-16.

38. Nouri F, Feizi A, Mohammadifard N, et al. Methods of sampling and sample size determination of a comprehensive integrated community-based interventional trial: Isfahan Healthy Heart Program. ARYA Atheroscler. 2018;14:58-70.

39. Moghaddam MB, Aghdam FB, Jafarabadi MA, et al. The Iranian Version of International Physical Activity Questionnaire (IPAQ) in Iran: content and construct validity, factor structure, internal consistency and stability. World Appl Sci J. 2012;18:1073-80.

40. Vasheghani-Farahani A, Tahmasbi M, Asheri H, et al. The Persian, last 7-day, long form of the International Physical Activity Questionnaire: translation and validation study. Asian J Sports Med. 2011;2:106-16.
41. Roohafza H, Sadeghi M, Shirani S, et al. Association of socioeconomic status and life-style factors with coping strategies in Isfahan Healthy Heart Program. Iran Croat Med J. 2009;50:380-6.

42. Mohammadifard N, Sajjadi F, Maghroun M, et al. Validation of a simplified food frequency questionnaire for the assessment of dietary habits in Iranian adults: Isfahan Healthy Heart Program. Iran ARYA Atheroscler. 2015;11:139-46.

43. Mohammadifard N, Kelishadi R, Safavi M, et al. Effect of a communitybased intervention on nutritional behaviour in a developing country setting: the Isfahan Healthy Heart Programme. Public Health Nutr. 2009:12:1422-30.

44 Skevington SM, Lotfy M, O'Connell KA. The World Health Organization's WHOQOL-BREF quality of life assessment: psychometric properties and results of the international field trial. A report from the WHOQOL group. Qual Life Res. 2004;13:299-310.

45. Jahanlou AS, Karami NA. WHO quality of life-BREF 26 questionnaire: reliability and validity of the Persian version and compare it with Iranian diabetics quality of life questionnaire in diabetic patients. Prim Care Diabetes. 2011;5:103-7.

46. Usefy A, Ghassemi GR, Sarrafzadegan N, et al. Psychometric properties of the WHOQOL-BREF in an Iranian adult sample. Community Ment Health J. 2010;46:139-47.

47. Marsh HWHK, Wen Z. In search of golden rules: Comment on hypothesistesting approaches to setting cutoff values for fit indexes and dangers in overgeneralizing Hu and Bentler's (1999) findings. Struct Equ Model. 2004;11:320-41.

48. Reise SP, Revicki DA. Handbook of item response theory modeling: applications to typical performance assessment. Routledge; 2014.

49. Smith $A B$, Fallowfield $L$, Stark DP, et al. A Rasch and confirmatory factor analysis of the General Health Questionnaire (GHQ)-12. Health Qual Life Outcomes. 2010:8:1-10.

50. Abubakar AFR. The factor structure of the 12-item General Health Questionnaire in a literate Kenyan population. Stress Health. 2012;28:248-54.

51. Batchelor JHMC. Extreme response style: a meta-analysis. J Organ Psychol. 2016;16:51-62.

\section{Publisher's Note}

Springer Nature remains neutral with regard to jurisdictional claims in published maps and institutional affiliations.
Ready to submit your research? Choose BMC and benefit from:

- fast, convenient online submission

- thorough peer review by experienced researchers in your field

- rapid publication on acceptance

- support for research data, including large and complex data types

- gold Open Access which fosters wider collaboration and increased citations

- maximum visibility for your research: over 100M website views per year

At BMC, research is always in progress.

Learn more biomedcentral.com/submissions 